\title{
EU Horizon 2020 programme: promoting user centric co-creative projects
}

\author{
Lopez-Plana, J. Oriol \\ Universitat Autònoma de Barcelona, Spain
}

\begin{abstract}
European Union Horizon 2020 programme has funded Research and Innovation projects over 7 years (2014 to 2020). This fund has promoted user centric co-creative projects such as REBUILD, TRACTION, and SO-CLOSE. REBUILD project is an ICT-enabled integration facilitator and life rebuilding guidance, TRACTION project is an opera co-creation for a social transformation, and SO-CLOSE aims at enhancing social cohesion through sharing the cultural heritage of forced migrations. These three projects have in common that they facilitate migrants integration through different user centric design strategies. This paper will 1) describe how these projects fit within H2020 strategy, 2) analyse in detail how these H2O2O projects approach user centric design, 3) detail the use of artistic tools at the three projects, and 4) conclude with key common findings.
\end{abstract}

Keywords: H2020, REBUILD, TRACTION, SOCLOSE, Co-creation.

\section{Introduction}

Horizon 2020 is the financial instrument implementing the Innovation Union, a Europe 2020 flagship initiative aimed at securing Europe's global competitiveness.

Seen as a means to drive economic growth and create jobs, Horizon 2020 has the political backing of Europe's leaders and the Members of the European Parliament. They agreed that research is an investment in our future and so put it at the heart of the EU's blueprint for smart, sustainable and inclusive growth and jobs.

By coupling research and innovation, Horizon 2020 is helping to achieve this with its emphasis on excellent science, industrial leadership and tackling societal challenges. The goal is to ensure Europe produces world-class science, removes barriers to innovation and makes it easier for the public and private sectors to work together in delivering innovation.

This paper is aimed at sharing three $\mathrm{H} 2020$ funded projects: REBUILD, TRACTION and SO-CLOSE. Three projects that have been created for improving migrants integration by facilitating user centric co-created strategies. REBUILD, TRACTION and SO-CLOSE are projects that were awarded funding from MIGRATION ${ }^{2}$ and TRANSFORMATIONS ${ }^{3} 2019$ calls.

MIGRATION call aimed at "Addressing the challenge of migrant integration through ICT-enabled solutions". The call stated:
An efficient management of migrant integration requires clear understanding of migrants' personal and family situation, including their legal status, origin, cultural background, skills, language skills, medical records, etc. Once such information is available to public authorities, it can improve societal outcomes to the benefit of both host countries and migrants. The integration of migrants, including refugees, in many Member States of the European Union and Associated Countries remains a challenge for both public authorities and local communities. ICT-enabled solutions and toolkits for the implementation of inclusion policies by public administrations may facilitate the management of the integration of migrants, improve autonomy and inclusion and therefore the lives of migrants. Such tools may help alleviate the tasks of public administrations and local authorities. They may also analyse available data and provide migrants with information on and easy access to relevant public services specific to their needs or support policy-makers and public administration at all levels in planning and taking decisions on migration-related issues through data analytics and simulation tools. The specific cultural features, including possible gender differences, the skills and capacities of migrants to express their needs as well as the equity of access to ICT may be considered in this regard.

REBUILD ${ }^{4}$ project is an ICT-enabled integration facilitator and life rebuilding guidance. It was submitted at MIGRATION call and it was awarded due to its mechanisms to promote smart, sustainable and inclusive growth, and as Trusted organisations, practices, services and policies that are necessary to build resilient, inclusive, participatory, open and creative societies in Europe, in particular taking into account migration, integration and demographic change.

TRANSFORMATIONS call suggested to find "Collaborative approaches to cultural heritage for social cohesion". The call stated:

Proposals should develop strategies for fostering collaborative and participative approaches to cultural encounters via communication channels such as social media platforms, participatory approaches, art and co-designed activities. Proposals should consider both tangible and intangible heritage, researching new applications and tools that allow for a more inclusive approach such as digital tagging of objects or co-authoring of societal and place-based memories. The active involvement and engagement with different groups or communities such as migrants and other communities at risk of exclusion should be promoted. Proposals should design options for these social groups to review or shape both contemporary and historical content, contribute new material or customise and personalise cultural heritage and digital humanities content in a meaningful and 
effective way. Collaborative tools and applications should help the cultural tourism sectors and cultural heritage institutions, NGOs, community organisations etc. in Europe and beyond to enhance the analysis and understanding of cultures and communities.

TRACTION $^{5}$ project is an opera co-creation for a social transformation. SO-CLOSE ${ }^{6}$ project aims at enhancing social cohesion through sharing the cultural heritage of forced migrations. Both projects were submitted at TRANSFORMATIONS as Research and Innovation actions and were awarded to study European cultural heritage to better understand the present, and to research into European regions' culture and how it has informed contemporary European diversity.

REBUILD, TRACTION and SO-CLOSE facilitate user centric co-creative strategies to define their impact, and the three projects promote artistic tools to vertebrate their work plan in different manner. This paper will further describe how artistic tools are used to design project outputs.

\section{Applying user-centered design}

For many years, user-centered design has been recognized as an approach that focuses on the needs of end users to guide the design of products, services, and systems (Gould \& Lewis, 1985; Norman , 2013). Some Research and Innovation actions under H2020 programme have used user-centered design approach for testing products, services, and systems. (Matamala and Orero, 2017).

\section{REBUILD}

REBUILD approaches user-centric design to limit any possible gender imbalance. Given the fact that the project follows a User-Centric design approach, REBUILD actively explores and considers possible gender differences in technology use, treatment adherence and validation in order to make sure that tests provided are attractive and motivating to both genders. REBUILD will support individual differences, promote gender equality, gender-specific instruction, and evaluation. Specific goals and methodologies for identifying gender aspects include service design, collation and processing user input (for both genders of refugees) in order to identify needs for user groups. This will be done by identifying relevant factors or variables and identifying gender specific market and product needs.

\section{TRACTION}

TRACTION approaches user-centric design to emphasize user participation. User-centred design (UCD) and human-centred design (HCD) methods tend to emphasize user participation in the design process for ideation and evaluation of design options (Ritter et al. 2014). However, UC/HC co-design or and co-creation methodologies have been focusing on user interaction, while applying to community interaction. Following Spinuzzi (2005) participatory design is a continuous participation of users involved with mechanisms for co-design at multiple stages. Enhancing and building capacities in communities and organisations to self-define problems while choosing the most suitable strategies to act is emerging as a very essence of strategic design, as described by Burns et al. (2006), Meroni (2008) and Zurlo (2010). According to Meroni (2011) community-centric design (CCD) is an approach that scales up the consolidated methods and tools of UCD/HCD to community size, where the emphasis is on understanding social behaviours and needs and then on collaborating with the most active social communities in conceiving solutions, adopting an inductive approach (Ogilvy 2002; Manzini 2008) and fostering transformation. Combining UCD/HCD and CCD through technology (Brandtzæg et al. 2010) allows to enhance local communities in each node, providing additional possibilities for the building of relationships, identities and new ways to foster social cohesion. It is important to improve local social ties and to promote interaction among people in local communities to achieve social cohesion (Geerts et al. 2007). Technology in this sense is an effective tool to foster social cohesion and empower transformation (Obrist et al. 2008). Within this project, community dialogue, co-creation and co-design processes in the three nodes will be empowered by an interactive toolset and a platform to exchange user-generated audio/visual content.

\section{SO-CLOSE}

SO-CLOSE approaches user-centric design to pilot and validate tools. Co-design is a user-centred methodology that treats users (in SO-CLOSE case, the refugees and the target audiences from the local societies) as experts in their own experiences. SO-CLOSE aims to deepen an equal collaboration between people affected by similar memories of forced displacement or migration. Moreover, the refugees and the receiving societies in Europe are attempting to resolve a particular challenge: how to overcome the negative memories of the past and to build a new cultural heritage based on tolerance and cooperation.

The co-design process has three phases: encounter, pilot, validation. The encounter will be in person and will be facilitated by the specialists from the SO-CLOSE participating institutions. SO-CLOSE facilitators will help the refugees and the representatives of the local target audiences (including, where possible, survivors) engage with each other, and will provide ways to communicate, be creative, share insights and test out new ideas. These moderators will use established strategies such as create user personas, storyboards and user journeys that chart the personal experiences to find shared features. Potential solutions to the challenge of finding a shared experience of the traumatic past can be tested through prototyping and scenario generation techniques. This input will be given to the technology experts who will design the corresponding digital tools; it will also be the basis of co-design methodology templates, one of the innovative outcomes of the project, that can be replicated in various locations across Europe. In the 
phase of piloting and validation, the four prototypes and tools generated earlier will be implemented in four concrete locations, using the digital shells as a way for the cultural encounter. The SO-CLOSE academics and cultural practitioners, together with the tech specialists, will monitor the implementation, will remedy any issues appearing on site, and will document the process. To validate them, the digital tools will be implemented in different locations, following the instructions gathered in the how-to manuals. If successful, the implementation of the tools in a new location effectively validates them and the co-design templates created.

\section{Artistic tools for co-creative projects}

Artistic tools vertebrate co-creative processes. Artistic tools and innovation walk hand in hand throughout co-creative processes: facilitators can use artistic tools for workshops, and projects can deliver artistic tools as outputs for their users. Also, artistic tools play a key role when interacting with participants at user centric processes.

REBUILD, TRACTION and SO-CLOSE use artistic tools in diferente manner. At this section the three projects will be presented in more detail and the author will put more emphasis on how artistic tools are being embedded in the work plan.

\section{REBUILD}

The REBUILD proposal address immigrant integration through the provision of a toolbox of ICT-based solutions that will improve both the management procedures of the local authorities and the life quality of the migrants. The design approach is user-centered and participated: both target groups (immigrants/refugees and local public services providers) will be part of the user requirement analysis and participants in three 2-days Co-Creation workshops organized in the 3 main piloting countries: Italy, Spain and Greece, chosen also for their being the "'access gates"' to Europe for main immigration routes. Users and stakeholders engagement is a key success factor addressed both in the Consortium composition and in its capacity to engage relevant stakeholders external to the project. The key technology solutions proposed are: GDPR-compliant migrants' integration related background information gathering with user consent and anonymization of personal information; Al-based profile analysis to enable both personalized support and policy making on migration-related issues; Al-based needs matching tool, to match migrant needs and skills with services provided by local authorities in EU countries and labor market needs at local and regional level; a digital companion for migrants enabling personalized two-way communication using chatbots to provide them smart support for easy access to local services (training, health, employment, welfare, etc.) and assessment of the level of integration and understanding of the new society, while providing to local authorities data-driven, easy to use decision supporting tools for enhancing capacities and effectiveness in service provision. Cross-culturality, ethical, accessibility dimensions will be addressed since the very beginning of the project, and validated and assessed in terms of consistency and impact during the project lifespan.

REBUILD specific objectives are 1) Coherent and tailored approach integration needs based data gathering. Gathering of background information on Migrants and local service providers; 2) Al-based profile analysis; 3) Needs and skills matching tool to support Public Authorities in the Refugees and migrants management and inclusion; 4) Digital companion: Communication and information hub for local population and Public Authorities; 5) Privacy and Data Protection-compliance of data gathering and processing; 6) Cross culturality (Multilinguality and multimodality); and 7) Map the socio-economic impact of the REBUILD activities and project scalability.

Artistic tools are planned to be used for co-creation workshops. REBUILD comprises 10 Work Packages. WP10 is responsible for the overall success of the project. WP1 is responsible of defining the methodology for data gathering and WP2 is in charge of specifying the requirements, analysing the specification, and providing the users scenarios. As such, it gives input to the purely technical work packages, i.e, WP3 and WP4, which design and implement the REBUILD technical components. The system is integrated and technically validated in WP5, while the deployment and the pilots are implemented in WP6. WP8 is responsible for the project dissemination activities. Finally, WP7 and WP9 are in charge of defining the ethical and legal framework and the cross culturality aspects as well as the evaluation of the socio-economic impact of REBUILD, thus they are represented as embracing all over work packages.

Also, artistic tools such as pictograms for the APP are a key element of REBUILD project. Jimenez-Andres $\mathrm{PhD}$ (in process) ${ }^{7}$ describe that

In 2016, United Nations High Commissioner for Refugees called for the use of mobile and internet technologies to tackle refugee's needs. Hence, in the last couple of years, there has been an increase in the number of ICT tools aimed at refugee and migrant populations. However, refugee populations are a heterogeneous group with diverse needs, literacy levels and linguistic capabilities, which are not always observed by the existing tools.

The objective of this $\mathrm{PhD}$ thesis is the creation and incorporation of a non-verbal language to ICT tools, specifically mobile apps, to bridge the communication gap. Through the use pictograms, this non-verbal language will allow communication with illiterate users and with users who speak languages which are not supported the app.

\section{TRACTION}

Opera uses all the visual and performing arts to create extraordinary worlds of passion and sensibility. It is rightly recognized as a great achievement of European culture. And yet a form that once inspired social and artistic revolutions is often seen as the staid preserve of the elite. With rising inequality and social exclusion, many see opera-if they think of it at all-as symbolic of what is wrong in Europe today. TRACTION 
aims to change that using opera as a path for social and cultural inclusion, making it once again a force for radical transformation.

TRACTION does not want to make opera palatable to those who don't attend. TRACTION wants to define new forms of artistic creation through which the most marginalised groups (migrants, the rural poor, young offenders and others) can work with artists to tell the stories that matter now. By combining best practice in participatory art with digital technology's innovations of language, form and process, TRACTION will define new approaches to co-creation and innovate in three fields: a) Opera creation and production; b) Immersive and interactive digital media; and c) Social integration and community development.

Experimental projects in inner-city Barcelona (ES), a youth prison in Leiria (PT) and rural communities in Ireland will test and share new ideas. Bridging the social and cultural divides involved will challenge many existing beliefs, structures and habits. The exceptional resources of the TRACTION partnership will help us meet that challenge through mutual support. The outcomes of TRACTION will be multi-dimensional. The areas of most confidence relate to the social outcomes for community participants: new skills, capacity and confidence, enhanced social networks and integration; better access to education and employment; increase in well-being, mental health and quality of life; stronger NGOs and community organisations. There will be similarly profound change for the opera artists and other professionals, who will develop a range of new ideas, resources and methods in relation to working with the community and co-creation. There will be a significant impact on opera creation methods and the language of the form itself, that will have a lasting influence on the future work of the organisations involved. Finally, there will be an important impact on the relationship between opera and digital technology, as new tools and technologies are developed, piloted and enhanced. This will certainly create valuable new knowledge and it has the potential to enrich market opportunities in different fields.

TRACTION specific objectives are 1) Promote, through their empowerment, a transformation of communities at risk of exclusion; 2) Establish an effective collaborative and participatory production workflow for the co-creation and co-design of art representations; 3) Lay down a community-centric methodology to conduct an efficient and measurable community dialogue that will last in time and be replicable; 4) Explore novel audiovisual formats based in European cultural heritage, such as opera; and 5) Maximise the social and market impact of the TRACTION results.

Artistic tools are much present throughout the project. TRACTION aimed to maximise the interaction among WP and make all the efforts converge at first towards the experimentation, prototyping and demonstration and later towards knowledge transfer and exploitation. TRACTION has therefore decided to organise the overall project around three axes: the research, design and implementation of the TRACTION workflow and toolset, the social co-designed opera across three main trials, and a community-centric methodology and validation. The dissemination, consolidation and exploitation, including the innovation management for the technology transfer, will be used as a meeting point for all the different efforts. WP1: Management, overall coordination of the project and the consortium, including a creative artistic and social management leading figure. WP2: Toolset Design and Development, responsible for 1 ) the specification of the technical requirements and the definition of the overall architecture; 2) the creation of the TRACTION toolset; and 3) the integration of the toolset, ensuring media accessibility services are provided across the whole workflow. WP3: Community Opera Co-creation, in charge of the co-creation of community operas across three main trials and cross-fertilisation workshops. The first trial will be a community opera with migrants, with the epicentre in the Raval neighbourhood in Barcelona and led by LICEU. The second trial will be led by SAMP, for opera cocreation with inmates in prisons, with the epicentre in a prison in Leiria, Portugal. The third trial will be representing Ireland's hidden stories through digital opera, led by INO and focusing in areas such as the Gaeltacht, the Midlands and inner-city Dublin and how these communities connected with each other. This WP will consider all the phases along the co-creation process: the community dialogue, the co-creation stage and training workshops, the production phase and representation phase for novel opera formats. WP4: Community-centric Methodology and Validation will focus on creating a methodology centred in end users to later perform a validation and user evaluation across different levels: technical evaluation and UX evaluation of the TRACTION toolset, evaluation of the co-creation and training phase, evaluation of the representation process, including opera full performances and digital capsules, and the measurement of the social transformation impact. WP5: Dissemination, Consolidation and Exploitation will be in constant interaction with research, artistic, social and industrial stakeholders, gathering feedback and disseminating the work done by the consortium through the larger community, including Advisory Board members and other relevant associations. WP5 will also lead the definition of resilient strategies which will consolidate the transformation beyond the end of the project.

\section{SO-CLOSE}

The ambition of the project is to contribute to social cohesion and fight refugee marginalization or exclusion by facilitating the encounters between similar life stories, through the mediation of innovative digital and artistic tools. Based on theories of cultural heritage-making, exposing the commonalities of past and present experiences, listening to the target groups' needs and through the development of a methodology template of co-creative design of replicable digital tools and cultural products, SO-CLOSE will improve social cohesion and promote mutual understanding between refugees and their local communities. 
The resulting data and methodology will be used to develop several digital applications, for which purpose we have in our consortium strong technological partners with experience in this field. Working at the intersection of history, sociology, cultural studies, art and computer science, SO-CLOSE will design educational and cultural tools like interactive cookbooks, interactive documentaries based on immersive video recording, Al-powered Chatbots, interactive exhibitions based on personal memories and storytelling or an online platform, named Memory Center, built as a content aggregator and services platform.

SO-CLOSE development will be implemented in four different pilot locations, selected due to their similarities with the present and for the actual existence of memory and intangible cultural heritage: 1) Villa Decius, Krakow (Poland); 2) Trikeri Island Concentration Camp (Greece); 3) MUME de l'Exili (Spain); and 4) Monte Sole (Italy).

Planned Memory Center interactive platform with its embedded repository of multimedia content and advances services, will be a global instrument transforming old-fashioned museums in Living Labs through designing new cultural experiences based on the cultural heritage of refugees addressing to generate social awareness.

The main objective of SO-CLOSE is to identify, analyse and match similarities of personal and collective traumatic experiences through storytelling between former and current refugees in Europe. Providing an inclusive and participative access to cultural heritage, SO-CLOSE will foster mutual understanding between refugees and the receiving European societies, thus contributing to social cohesion and ultimately to integration. The project will achieve this aim through the creation and implementation of innovations in three fields: methodology (participatory and collaborative design), technology (digital cultural heritage applications) and content (locally-created narratives that mix past and present experiences of forced migration).

SO-CLOSE specific objectives are 1) Foster cultural and social encounters between forced migrants from past and nowadays conflicts in order to promote mutual cultural and life-experience understanding; 2) Strengthen social integration of refugees through the participation and design of cultural experiences using resources such as digital storytelling, photography, mapping, documentary, etc, allowing the target groups recounting their narratives on their own terms; 3) Design new cultural experiences based on the cultural heritage of refugees addressing to generate social awareness; 4) Transform cultural institutions (such as museums, memorials or cultural centres) in LIVING LABS with the capacity to generate new cultural contents, immersive, adaptable and customizable; 5) Develop a common platform for cultural heritage negotiation and development for refugees and the receiving European societies; 6) Transform the negative perception of many European citizens towards the situation of refugees and the current migration crisis; and 7) Review the contemporary and historical content of forced migration in Europe and beyond.
Artistic tools will facilitate co-creation workshops but also will be a final output of the project. The SO-CLOSE project will be structured in six Work Packages. After an initial phase for refining and agreeing on a common methodology (WP1), the project will co-design (WP2) and develop (WP3) a set of tools allowing the co-creation of new cultural materials based on historical and present experiences from refugees (WP4). Two transversal WP will also be active during the whole project (WP5, WP6). WP5 will deal with the exploitation and dissemination of the project results, including communication activities and a replicability \& sustainability assessment. Finally, WP6 will deal with management to ensure the accomplishment of the project objectives while complying with open data and ethics requirements.

It is interesting to further describe WP2, WP3 and WP4, their interaction, and how artistic tools are used. The main objective of WP2 is producing the co-design methodology, including the required practical tools and moments for the mediation of cultural encounters. In this WP the consortium launches the encounter experiences in four local venues, connected to consortium's four partners interfacing with refugees: Villa Decius Association (Krakow), Monte Sole Peace School (Monte Sole), Memorial Museum of Exiles (La Jonquera) and Greek Forum of Refugees together with the affiliated Contemporary Social History Archives (Trikeri). WP2 will be used for the collection of first hand experiences and memories of both refugees and local communities with experience of the tragedies of deportation, migration and exile; these stories and the materials that accompany them, will be described, translated, transcribed and made available to users (cultural institutions, researchers, the general public). With the participation of target groups' representatives selected in WP1, each venue will develop its own activity of exchange and dialogue between past and present. During these exchange activities, the data that WP3 will use for the development of technological tools and WP4 will use for the development of activities and pilots, including a final repository of all detailed, described and digitalised materials, and eventually as a source for educational tools. All the selected target groups, researchers, cultural institutions and technology providers will develop the co-creation of new digital tools through a two-step experience: 1) exchange activities, where the selected target group receives the input from the past experience in museum experiences, survivors talks, seminars, historical walks and debate in specific workshops with cultural institutions, artists, activists and technology providers about how new tools can be implemented (educational tools, virtual reality, virtual museum, short films, video-games / apps); 2) data collection on heritage and storytelling. The main goal of WP3 is twofold. On one hand it has to develop a set of tools to enable the sharing of cultural heritage and the co-creation of new cultural materials with and for refugees. On the other hand, this WP will also develop the Memory Center, an accessible multimodal platform that will gather the new materials created by SO-CLOSE in different locations 
to connect them with similar initiatives and reach broader and different targets (academic, arts, public authorities, and the whole society).

In WP4, the main goal is to implement and validate the digital tools resulting from the work in previous work packages in four concrete locations (Villa Decius, Trikeri, Monte Sole, La Jonquera) and to co-create locally based contents. The specific objectives are: o implement and test the digital toolboxes in several locations; To document the process of local adaptation, local content co-creation and testing; To generate co-created content that fills the digital tool "shells" designed in WP3; To address the on-site problems that might occur and include them in a troubleshooting section of the how-to manual; and To evaluate the quality of the tools and of the process.

\section{Conclusion}

User-centric design aims at creating services, products and systems from starting from user needs. The three presented $\mathrm{H} 2020$ projects are approaching user-centric design in their processes: REBUILD approaches user-centric design to limit any possible gender imbalance, TRACTION approaches user-centric design to emphasize user participation, and SO-CLOSE approaches user-centric design to pilot and validate tools.

For applying user-centric design, projects had to plan workshops where different stakeholders participated. Artistic tools can be used for facilitating these workshops, as a final output of the project, and for improving certain processes. At REBUILD, artistic tools are planned to be used for co-creation workshops, TRACTION uses artistic tools to facilitate migrants integration, and SO-CLOSE is creating artistic tools for building bridges between past and present migrations.

EU strategy for implementing the Innovation Union has to be acknowledged. H2020 Research and Innovation programme has ended but the new Horizon Europe ${ }^{8}$ seems to be the next cutting-edge fund through its three pillars (Excellent Science, Global Challenges and European Industrial Competitiveness, and Innovative Europe).

\section{Final notes}

This research is part of the article-based $\mathrm{PhD}$ thesis of the first author conducted in the Department of Translation and Interpretation in the Autonomous University of Barcelona (UAB) within the PhD program in Translation and Intercultural Studies. This research has been partially funded by the $\mathrm{H} 2020$ project SO-CLOSE (GA 870939), by the Catalan Government AGAUR scholarship (2020DI49), and SGR2017-113.

\section{Notes}

${ }^{1}$ https://ec.europa.eu/programmes/horizon2020/

2 https://cordis.europa.eu/programme/id/H2020_DT-MIGRA TION-06-2018-2019

${ }^{3}$ https://cordis.europa.eu/programme/id/H2020_DT-TRANS FORMATIONS-11-2019

${ }^{4}$ https://cordis.europa.eu/project/id/822215

${ }^{5} \mathrm{https}: / /$ cordis.europa.eu/project/id/870610

${ }^{6} \mathrm{https}: / /$ cordis.europa.eu/project/id/870939

${ }^{7}$ https://pagines.uab.cat/doctorat-traduccio/en/node/1413

${ }^{8} \mathrm{https}: / /$ ec.europa.eu/info/horizon-europe_en

\section{References}

Brandtzæg, Petter Bae, Asbjørn Følstad, Marianna Obrist, and David Geerts. 2009. "Innovation in online communities-towards community-centric design." International Conference on User Centric Media. Springer, Berlin, Heidelberg.

Burns, Colin, Hilary Cottam, Chris Vanstone, Jennie Winhall. 2006. "RED paper 02: Transformation design." London: Design Council.

Geerts, David, Marianna Obrist, Manfred Tscheligi S, and Brandtzæg, Petter Bae. 2007. "Supporting nonprofessional users in the new media landscape." $\mathrm{CHI} 07$ Extended Abstracts on Human Factors in Computing Systems.

Gould, John D, and Clayton Lewis. 1985. "Designing for usability: key principles and what designers think." Communications of the ACM 28.3: 300-311.

Manzini, Ezio. 2008. "Collaborative organisations and enabling solutions. Social innovation and design for sustainability." Collaborative services. Social innovation and design for sustainability 29-41.

Matamala, Anna, and Pilar Orero. 2017. "Audio Description and Social Accessibility" RIIT 19: 7-12.

Meroni, Anna. 2008. "Strategic design: Where are we now? Reflection around the foundations of recent discipline". Strategic Design Research Journal 1:31-38.

Meroni, Anna. 2011. "Design for services and place development. Interactions and relations as ways of thinking about places: the case of periurban areas." Shanghai Young Creators For Better City \& Better Life. University of Art and Design Helsinki.

Norman, Don. 2013. The design of everyday things: Revised and expanded edition. Basic books.

Obrist, Marianna, Elke Beck, Sara Kepplinger, and Regina Bernhaupt. 2008. "Local Communities: Back to Life (Live) Through IPTV." European Conference on Interactive Television. Springer, Berlin, Heidelberg.

Ogilvy, James A. 2002. Creating better futures: Scenario planning as a tool for a better tomorrow. Oxford University Press.

Ritter, Frank E., Gordon D. Baxter, and Elizabeth F. Churchill. 2014. "User-centered systems design: a brief history." Foundations for designing user-centered systems. Springer, London, 2014. 33-54.

Spinuzzi, Clay. 2005. "The methodology of participatory design." Technical communication 52.2: 163-174.

Zurlo, Francesco. 2010. "Design Strategico". In: AA. VV,. Glispazi e learti, Volume IV, Opera XXI Secolo. Roma: Editora Enciclopédia Treccani. 